\title{
THE EMPLOYMENT HISTORY OF DAY LABOURERS IN South AFrica ANd THE INCOME THEY EARN - A case study of day labourers in Pretoria \\ Derick Blaauw \\ Department of Economics, University of Johannesburg \\ Huma Louw \& Rinie Schenck \\ Department of Social Work, University of South Africa
}

\begin{abstract}
Formal sector unemployment forces many workers to venture into the informal sector. The activities of day labourers are no exception. The aim of this paper is to address the lack of research on informal labour markets by focusing on the day labourers in Pretoria as a case study and to investigate the employment history of and income earned by day labourers in Pretoria.

Day labourers involved in this study were mainly male, young, low skilled, earning low and uncertain levels of income and working under harsh conditions. A significant portion of day labourers in Pretoria previously held formal sector occupations. Long spells of unemployment can make it difficult for day labourers to return to the formal sector. Many activities in the informal sector can never provide a permanent solution to unemployment.
\end{abstract}

Abstract

JEL J61, 64

\section{1}

\section{Introduction and aim of the paper}

\subsection{Introduction}

With the opening up of the South African economy, following its successful democratisation and adherence to a strict programme of trade liberalisation, the number of highly-skilled (professionals, managers and technicians) persons employed showed strong growth, while the number of less skilled persons in employment declined (Whiteford \& van Seventer, 1999: 3). Unemployment remains one of the major macroeconomic problems facing this country. The official unemployment rate in September 2005 was 26,7 per cent (Statistics South Africa, 2006a: iv). In spite of the recent positive news on the unemployment front, the foreseeable future is evidenced by large numbers of unemployed people.

Some people are unemployed for long periods of time. In order not to be dependent on other income earners for survival, they eventually have no other choice than to venture into the informal sector of the economy to raise income (Whiteford \& van Seventer, 1999: 3). The activities of day labourers developed as a result of this movement to the informal sector of the economy. Since the mid 1990s it has grown quite substantially from a very small base. Between 1997 and 2005, about 1.1 million jobs were created in the informal sector. Unfortunately the dynamics of the growth of the non-formal economy are poorly understood (Altman, 2006: $6)$.

One of the most visible forms of unemployed people are the men who stand at the side of the road every day, waiting patiently for any job that may come their way. According to Maisel (2003: 2) there are 500 places in South Africa where people are picked up for casual labour on an hourly or daily basis. With an average of 50 to 100 men per site per day, this amounts to between 25000 and 50000 men per day. The ages of these men vary between 16 and 25 , all unemployed and desperate to find work. 
Except for the occasional article in the daily press, very little research has been done on this informal labour market in South Africa. Schenck \& Louw (2005: 84-95) conducted a preliminary study in this field in Pretoria during 2003. This study was done from a social work perspective with little emphasis on the economic aspect of this labour market.

Kingdon \& Knight (2001a: 2) state that the investigation of unemployment in South Africa requires the availability of reliable microeconomic data, that is data collected directly from individuals or collected about individuals from their households. Studying the employment history of people involved in this informal labour market and the income earned by them, could provide valuable insight into the complex nature of unemployment in South Africa.

\subsection{Aim of the paper}

Against this background, the aim of this paper is twofold. The first objective is to address the lack of research on informal labour markets by focusing on day labourers in Pretoria as a case study.

The second objective is to investigate the employment history of day labourers in Pretoria and the income earned by them. It will provide data pertaining to the origin of the people in this part of the informal sector, that is whether formal sector employment was once held, for how long and the reasons for losing it. From the above analysis the viability of this informal activity as an alternative to formal sector employment will be determined. This will be done by looking at the income generated from this activity in comparison to accepted proxies for the minimum income needed to survive materially.

\section{2}

\section{South African literature on the informal sector}

Informal and flexible forms of labour are a historical characteristic of the South African labour market (Valodia, Lebani, Skinner \& Devey, 2006: 105). The South African informal sector has received more and more attention from researchers during the last two decades. Examples of this resultant research include Rogerson \& Beavon (1980), Krige (1988), Lund (1998), Muller (2003), Kingdon \& Knight (2001), Devey, Skinner \& Valodia (2003); Altman (2006), as well as Valodia, Lebani, Skinner \& Devey (2006). The consensus in the South African literature is that employment in the informal sector offers a second-best alternative to formal sector employment. Individuals, of whom the majority are Africans, unable to secure employment in the formal sector were forced to resort to informal means of employment, in one of a range of low-income marginal informal sector activities, in order to lead an existence of survival (Muller, 2003: 18).

There is however no clear consensus on either the accepted definition of the informal sector or the size of it in South Africa. One of the definitions of the informal sector is as follows: "Unorganised, unregulated and mostly legal but unregistered economic activities that are individually or family owned and use simple, labour-intensive technology" (Barker, 2003: xix). This coincides with Statistics South Africa's definition of informal sector employment, namely: “... unregistered business, run from homes, street pavements or other informal arrangements" (Statistics South Africa, 2003: xiii).

Devey, Skinner \& Valodia (2003: 7-8) state that some workers classified under the informal economy display characteristics of work that are considered to be formal. On the other hand, large numbers of workers classified under the formal economy display characteristics of work commonly associated with informal work. They propose therefore that South Africa should thus consider adopting a definition of informal work based on work characteristics. The following definition was proposed by the 2002 International Labour Conference and quoted by Devey et al. (2003: 45 - 46) as a suggestion: "The informal economy comprises informal employment (without secure contracts, worker benefits or social protection) of two kinds. The first is informal employment in informal enterprises (small unregistered or unincorporated enterprises) including employers, employees, own account operators and unpaid family workers in informal enterprises. The 
second is informal employment outside informal enterprises (for formal enterprises, for households or with no fixed employer), including: domestic workers, casual or day labourers, temporary or part-time workers, industrial outworkers (including homebased workers) and unregistered or undeclared workers."

The analysis of Devey et al. (2003: 45) further points out that the estimates of informal employment in South Africa, and hence of total employment, is variable and unreliable. According to the definition of the informal sector employed by the Central Statistical Office (the predecessor of Statistics South Africa) - which includes own account workers, persons involved in both own account and formal sector activities, domestic workers and persons whose sector of work is unspecified - the informal sector absorbed only 10 to 12 per cent of the total labour force in the years 1994 to 1999, according to the October Household Surveys (Kingdon \& Knight, 2001b: 5).

Other sources like Schlemmer and Levitz (1998) argue that the size of the informal sector in South Africa is underestimated and the unemployment rate overestimated because some people engaged in casual, small-scale self-employment or in illegal activities may not report these and they are counted as unemployed instead (Kingdon \& Knight, 2001b: 5).

Recent estimates in terms of the size of the informal sector include that of Altman (2006: 1 ), which states that about 15 per cent of the labour force relied on informal work in 2005. Valodia et al. (2006: 11) states that the sustained growth in employment in the informal economy must be treated with caution as the data used is not directly comparable. Because it is such an evident sector, Statistics South Africa has improved their capturing of the phenomenon.

Informal employment in South Africa, as well as in the rest of the world, comprises diverse activities. These include street vending, gardening, bricklaying, painting, sewing, driving, caring, operating a shop or spaza, hairdressing, welding, managing, and practising traditional medicine. This underlines the heterogeneous nature of the informal economy (Devey, Skinner \& Valodia, 2003: 28). Since 1995 these services have been extended to include car guarding services at shopping centres and other public places in the central business districts of metropolitan areas (Blaauw \& Bothma, 2003: 41). It must be noted, however, that the South African informal economy is dominated by retail and wholesale trade to disproportionate extent (Valodia et al., 2006: 114).

The skills levels required for various activities differ substantially. There are also significant differences in the various occupations in terms of gender, although some activities like street vending are conducted by both men and women (Devey et al., 2003: 28).

Some activities, for example car guarding, are merely survivalist in nature, yielding very low income. Other activities may offer potentially very high returns. In some cases these returns may even be higher than the average earnings in regular formal sector employment (Muller, 2003: 21).

\section{3}

\section{Literature on day labourers in Pretoria}

Unlike the case in the United States, literature on day labourers in South Africa is often limited to the occasional article in the daily press. For example, Mocke (2004: 12) published an article in the Beeld newspaper pertaining to the activities of day labourers. In South Africa there are thousands of unemployed people, standing at the side of the road, waiting for informal and in most cases temporary employment. The men she interviewed lead a harsh life. They must be satisfied with an average daily wage of between fifty and sixty Rand for a long day's work. They are willing to do anything, from garden work to the mixing of cement, painting, loading or unloading of heavy goods. They will do it because it is the only income they have. Many days go by without any work for many of these men.

The study by Schenck \& Louw (2005) of the Department of Social Work at the University of South Africa in the vicinity of the suburb of Elarduspark in Pretoria, highlighted similar results. These men work long hours and wait almost every day for employment in harsh climatic conditions. This study laid important 
groundwork in order to extend the research into a more thorough research project, encompassing the whole of Pretoria.

The next section provides a brief discussion of the research methodology employed in conducting the field work for the research.

\section{4 \\ Research methodology}

After a thorough literature study the questionnaire for the research project was developed. Since it was expected that some day labourers may be illiterate, the survey was in the form of scheduled and structured interviews. This method ensures that there is no misunderstandings and misinterpretation of questions (Bless \& Higson-Smith, 1995: 111). A questionnaire consisting of four sections was used for this purpose. The first three sections contained questions pertaining to the demographic features, income and working conditions of day labourers. A section was included to enable information to be extracted regarding the possible abuse of this vulnerable group in the economy.

Suitable fieldworkers were recruited and trained. This was followed up by a trial run of interviews. The completed questionnaires were evaluated in order to identify possible ambiguous questions. The final questionnaire was adjusted to take this, as well as the comments received from the fieldworkers into consideration.

Before the actual survey was conducted, a detailed reconnaissance of the greater Pretoria area was done to determine the size of the research population. The estimated number of day labourers in Pretoria was around 2420 persons.

To compile a stratified sample of 10 per cent, the research population was allocated proportionally between the various hiring sites in terms of size. The various hiring sites were therefore classified according to the number of workers standing at each site. Table 1 presents the classification of the sites according to size and site number.

Table 1

Classification of hiring sites according to size and site number

\begin{tabular}{|c|c|c|}
\hline Size of site & & Number of sites in each category \\
\hline Small sites: & $1-25$ people & 37 \\
\hline \multicolumn{3}{|l|}{ Medium sites: } \\
\hline Small-medium sites: & $26-35$ people & 11 \\
\hline Large-medium sites: & $36-50$ people & 10 \\
\hline Large sites: & $51-100$ people & 9 \\
\hline Mega sites: & 100 people + & 2 \\
\hline
\end{tabular}

From the above classification, three stratums; small, medium and large hiring sites were identified. A representative sample of 240 workers to be interviewed was selected.

The fieldworkers conducted the fieldwork over a period of four days from 27 to 30 September 2004. Interviewing started from 06:00 in the morning. A total of 242 questionnaires were completed in good order for the sample population.

The next section consists of the presentation and analysis of the empirical results in terms of the stated objectives.

\section{5 \\ The employment history of day labourers in Pretoria}

This section begins by describing the demographic features and working conditions of day labourers in Pretoria and provides the scientifically obtained information required by the first research question. 


\subsection{The demographic features and working conditions of day labourers in Pretoria}

The following demographic information was obtained pertaining to the origin of the day labourers active in the greater Pretoria area. As was expected the day labourers were almost exclusively male. Only six woman day labourers were among the respondents. The gender distribution therefore is 97.5 per cent and 2.5 per cent respectively for the male and female day labourers. This is to a large extent explained by the unprotected nature of the lives that day labourers lead. Out of the 242 respondents, 88 per cent were born in South Africa. The remaining portion was born in Zimbabwe (7 per cent) and Mozambique (2.9 per cent). Five respondents $(2.1$ per cent) did not want to specify their country of birth. It is expected that these men were also born outside the borders of South Africa.

A very interesting statistic is the fact that as many as 215 , or 88.8 per cent, of the day labourers interviewed came from outside the Gauteng province in order to seek employment in Pretoria. Almost 60 per cent of the day labourers came from the Limpopo and Mpumalanga provinces. This trend corresponds with the fact that a significant percentage of the respondents were born in Zimbabwe and Mozambique and use the respective provinces as their port of entry into South Africa. Almost one third of respondents indicated Sepedi as their home language. Isindebele and Xhitsonga is spoken by 15.8 and 10.4 per cent of the respondents respectively. Portuguese is the predominant language among the 5.7 per cent that indicate a language other than one of the official languages of South Africa.

Almost three quarters of the respondents in the survey is younger than thirty five years old. In fact, 61.2 per cent of the day labourers involved in the survey is younger than thirty. On average, each day labourer supports 4 people (including himself) with the income earned in this informal labour market. More than half of the respondents (56.2 per cent) supports up to four people, while 4.1 per cent of the respondents indicated that they support more than nine people with their income. By using the frequency results of the questionnaire, it is estimated that the informal labour market of day labourers provides some income for at least ten thousand people.

Day labourers interviewed in this survey displayed disappointing levels of formal schooling. Twelve respondents never attended school at all. This represents 5 per cent of the sample population. Seventy six (31.4 per cent) of the day labourers achieved the qualification of grade 11 and 14 per cent completed grade 12. This has a definite impact on their chances of obtaining a position in the formal sector of the labour market. Of those who answered this question, 162 respondents (77.1 per cent) cited a lack of financial support as the main reason for leaving school before completing their studies. The rest of the research population listed failing, lack of interest as well as various other reasons for leaving school.

In response to the question relating to any form of formal skills training received, as many as 99 people (40.9 per cent) admitted to having no formal training whatsoever. Although the other respondents suggested training in the fields of painting (13.6 per cent), security business ( 8.7 per cent), carpentry ( 5 per cent) as well as various other areas, no details on any formal qualification or completion of an apprenticeship was available. In general the skills level of day labourers is very low. The availability and level of skills of the labour force plays an increasingly important role in attracting foreign direct investment which creates future employment opportunities (Chetty, 2002: 10). There are therefore no positive prospects for their soon being able to return to the formal sector.

The next set of questions explored the working conditions of this informal labour market. The survivalist nature of this market is clearly illustrated by the fact that 51.2 per cent of the sample population stand and wait for work between five and six days per week. Forty eight respondents (19.8 per cent) indicated that they wait for all seven days of the week in the hope of finding employment. A working week of six and sometimes seven days per week puts a lot of strain on the social fabric of the community 
where these people live. Little time for relaxation and family does not augur well for the quality of life of the people involved in this industry. This is however the harsh reality of their lives. For most of them this is the only alternative available in a labour market that requires a lot more human capital than what they can offer. During the course of the interviews, the field workers became acutely aware of the social problems that exist among the day labourers.

Figure 1 provides a breakdown of the different activities or tasks that the day labourers in Pretoria were asked to perform when they were hired.

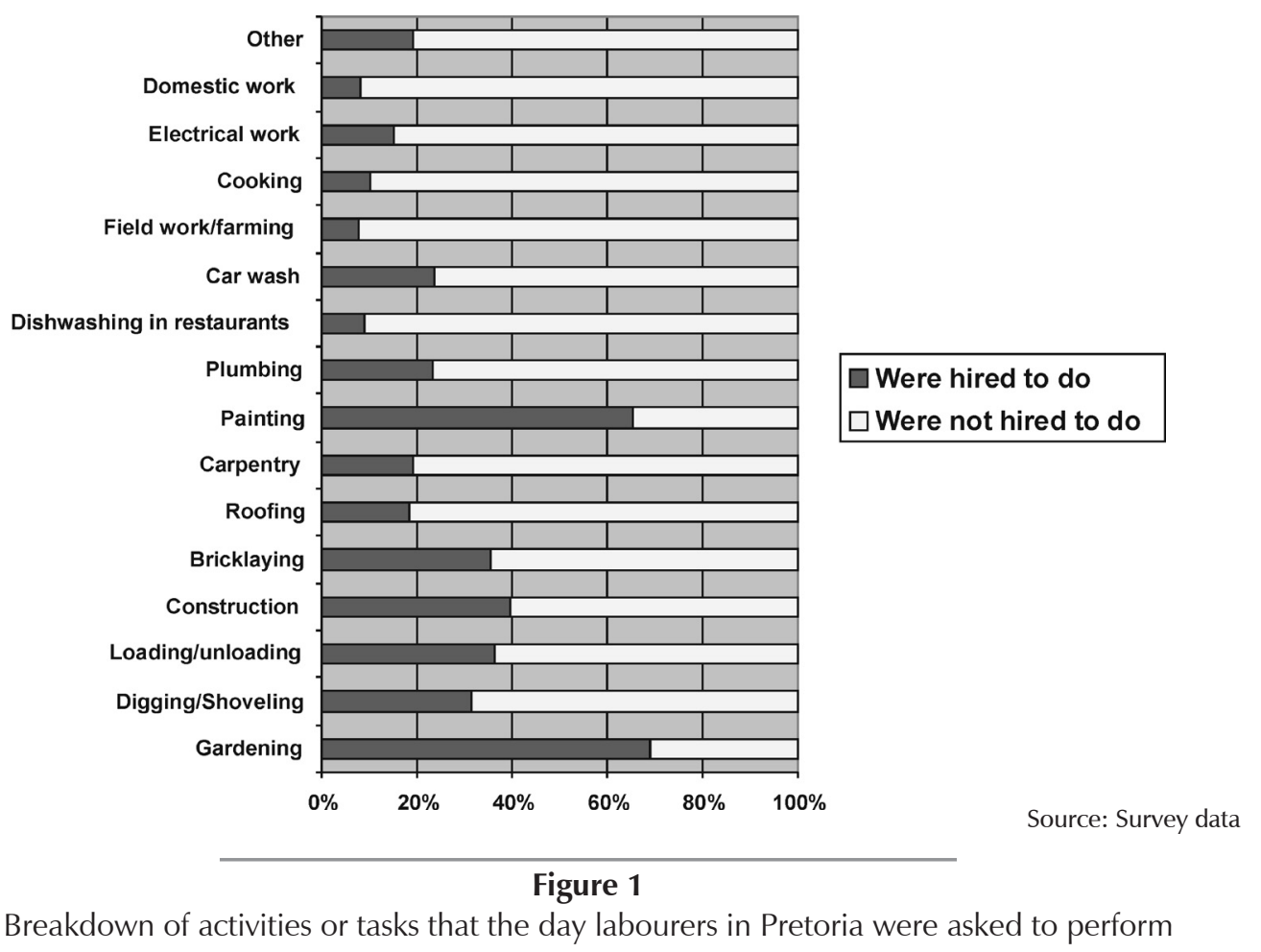

The biggest source of temporary employment for day labourers in Pretoria exists of gardening services and painting, with 69 and 65.3 per cent of the respondents testifying that they were hired at some point to do that kind of work. An interesting figure is the twenty ( 8.3 per cent) respondents indicated that they were hired to do domestic work. This corresponds with the percentage of the research population that were females. It is also interesting to note that nearly half of the day labourers involved in the survey, missed job opportunities at some stage due to lack of tools for it. A hundred and fifteen day labourers (48.1 per cent) were in this position at some stage or another.

Only seventy two day labourers get hired by the same employers repeatedly (more than three times). This represents only 30.1 per cent of the sample population. At the same time a mere 22.9 per cent of the respondents indicated that they have a regular job opportunity apart from looking for piece jobs. It is clear that the day labourers enjoy very little, if any, security in terms of the possibility of earning an income. No wonder then that two hundred and nineteen (90.1 per cent) of them maintained that they are looking for full-time employment.

No clear pattern emerges from the response of the day labourers in terms of the skills that they view as important to improve their employment opportunities. It is however evident that the significant percentage (15.2 per cent) who indicated the need for training in the construction sector of the economy, confirmed the improved performance of the South African economy. It is clear that the day labourers at 
grass roots level realised that this is an industry that demonstrates an increase in the demand for labour. The category "other skills" revealed a wide range of jobs, ranging from architecture, dressmaking, criminal investigative skills as well as obtaining a driver's licence. The interviewers gained appreciation for the need that exists for training and the expansion of the existing pool of human capital in this informal labour market.

In summary, the day labourers involved in this study were found to be mainly male, fairly young, generally very low skilled, experiencing no certainty in terms of income security, supporting on average four people and working under harsh conditions.

The next section analyses the results of the research in terms of the second stated objective namely, the investigation into the employment history of the people in this informal labour market.

\subsection{The employment history of day labourers in Pretoria}

It is important to determine how many of the current day labourers had full-time employment before becoming day labourers, as it will provide valuable insight into their origin and past labour market involvement. For this purpose a specific direct question was included in the questionnaire. The response led to an interesting observation regarding the past labour market involvement of day labourers in Pretoria. Figure 2 represents the aggregate result.

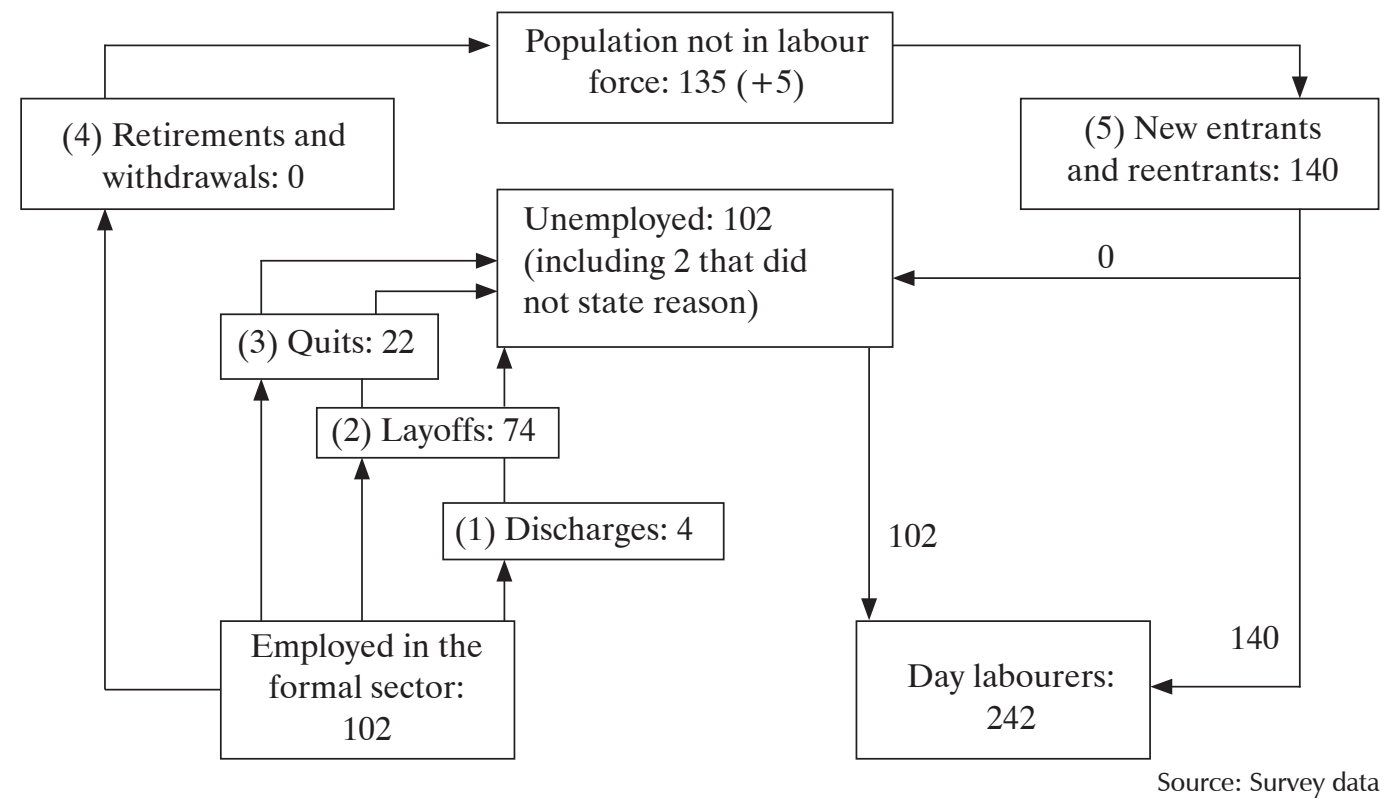

Figure 2

The past labour market involvement of day labourers in Pretoria

A hundred and two of the respondents maintain that they did in fact have permanent employment in the formal sector of the economy before becoming day labourers. This represents a significant 42.1 per cent of the sample. Five workers did not answer that particular question, leaving a hundred and thirty five (55.8 per cent) who did not have previous formal employment. They flowed straight from the "Population not in labour force" box of Figure 2 to the informal sector of the economy. Alternatively, they could have searched for employment for some time and therefore flowed from the "unemployed box" to the informal sector.

Figure 3 provides a breakdown of the previous employment that was held by the now day labourers in the formal sector of the economy. The number of workers in each category is expressed as a percentage of the sub sample, consisting of those who had previous employment. 


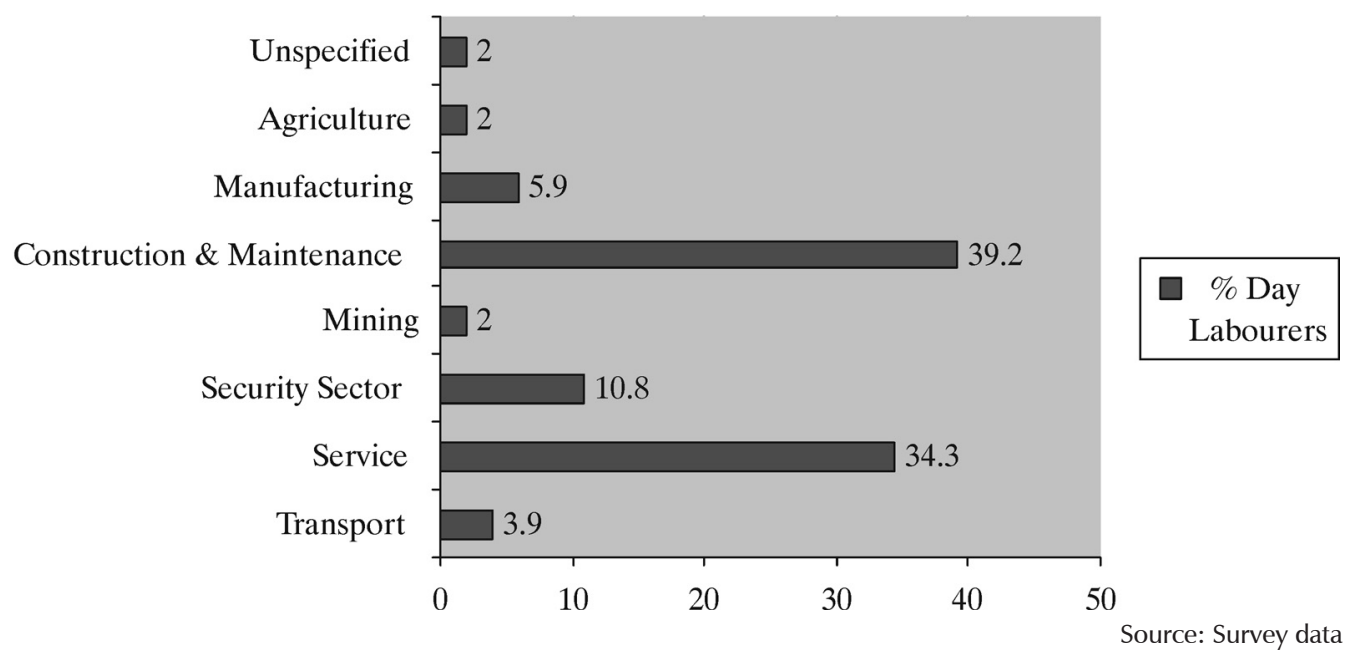

Figure 3

Previous employment of day labourers

Forty people (39.2 per cent of the sub sample) originated from the construction and maintenance sector of the formal economy, while 35 people were employed in the services sector and 11 people in the security industry. Given that the security industry can also be classified as a services industry it implies that half of the day labourers with previous full-time employment came from the services sector. This statistic corresponds with the findings of research done on another informal labour market, namely that of car guards in Bloemfontein in 2001 (Blaauw \& Bothma, 2003: 41).
In order to further appreciate the past labour market involvement of day labourers, it is important to determine the length of time that the day labourers were employed in the formal sector as well as the reasons for leaving it.

Figure 4 highlights the distribution of the responses of the sub sample to the question as to how long this formal sector employment was held. Once again the number of workers in each category is expressed as a percentage of the sub sample, consisting of those who had previous employment.

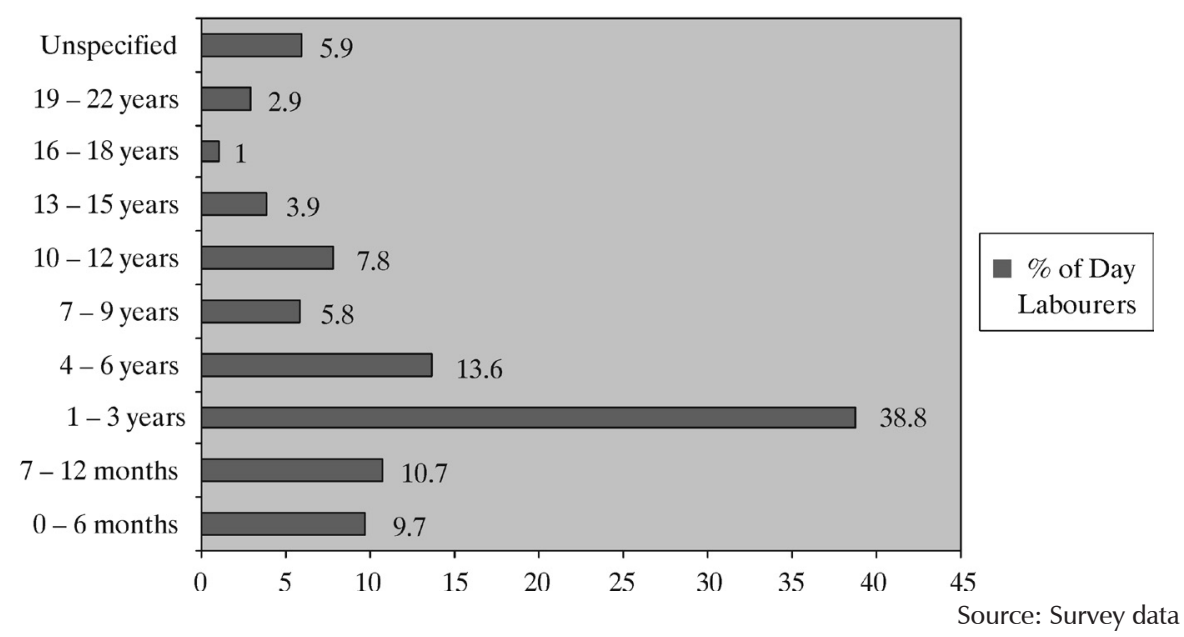

Figure 4

Length of time formal sector employment was held by day labourers 
Of the day labourers who were previously employed in the formal sector, 59.2 per cent worked there for a period of three years and less. If the distribution is calculated up to a period of six years, this figure increases to 72.8 per cent. An important minority of 21.4 per cent held employment for longer than 10 years. Three workers held positions in the formal sector for longer than 19 years. It is evident that many of the respondents held stable employment for a relatively long periods of time before becoming unemployed.

The low level of education of these people will make it difficult for them to obtain alternative employment opportunities in the formal sector of the economy, since the demand for low skilled labour in South Africa is continuously declining (Loots, 1998: 332). The longer these people stay unemployed, the faster their already low levels of human capital decline.

The important question as to why this formal sector employment was terminated is analysed next. Respondents were therefore also asked to state the reasons for leaving their previous employer.

Two of the 102 respondents refused to answer this question, but are still included in the "unemployed" box of figure 2. Seventy four were laid off, 22 quitted and four were discharged. Not one of the 102 retired and left the labour force.

The data shows that there are two major reasons for the flow from the formal sector of the economy to the "unemployed" box of figure 2 as far as the day labourers are concerned. Layoffs in the form of retrenchments and the closure of businesses were responsible for 71.9 per cent of the flow to the "unemployed" box. This follows the same trend observed in the informal labour market of car guards in Bloemfontein (Blaauw \& Bothma, 2003: 40-44).

The immediate assumption is that this is related to the business cycle and other economic reasons. Although this plays a major part, the fact is that there are important institutional factors at play as well. The six female day labourers encountered in this study are a classic case in point. They were all part of a bigger group of about twenty female workers in a dressmaking business. According to reports received from the fieldworkers they maintain that they were laid off in order for the business to stay smaller than the minimum size prescribed by the current labour legislation in terms of minimum wages and other conditions of employment. The business now hires those same workers as casual staff, in this way avoiding all the institutional cost involved in adhering to all the prescriptions of the relevant labour legislation. Retirements and voluntary withdrawals played no role in explaining this movement. Two surprising statistics came to the fore. One is the fact that more than twenty per cent of the respondents quit their full-time employment for reasons such as a wage that was considered to be too low, health reasons, etc. The second one is the 3.9 per cent of the day labourers who admitted that they were discharged for disciplinary reasons. The 2.9 per cent of the respondents that refused to answer the question may very well also fall in this category.

The 102 respondents who left the formal sector were joined in the informal labour market by the 135 day labourers who did not have previous employment, as well as the five day labourers who did not want to answer the question pertaining to this information. It is not entirely clear whether they were looking for other employment (that is flowed via the "unemployed" box before becoming day labourers) or whether they moved straight into this informal labour market. From the interviews it seems that they moved straight into this informal labour market and are now looking for permanent employment. In fact, 219 respondents ( 90.9 per cent) indicated that they would like to find other employment. This corresponds with the finding of Kingdon \& Knight (2001a: 15) that people outside the formal sector, except the few doing well in informal sector activities protected by barriers to entry, are avid for formal sector jobs.

This high percentage provides prima facie evidence that being a day labourer is not a viable alternative to full-time employment. In order to provide a scientific answer to this hypothesis, it is necessary to analyse the income earned by the people involved in this informal labour market. 
6

\section{An analysis of the income of day labourers in Pretoria in 2004}

The questionnaire made provision for two questions relating to the daily income earned by day labourers in Pretoria. A scatter diagram of the data indicates a negative relationship, with many of the day labourers receiving a wage much less than what they would have liked. For example, only 4.8 per cent of the respondents are prepared to work for a wage of between R41 and R50, while 26.4 per cent of them had to be satisfied with that. On the other end of the scale 26.2 per cent wanted more than R120 per day. However, only 0.4 per cent of the respondents received that wage.

Only a cumulative 16.7 per cent of the respondents are willing to accept a wage rate of between zero and R70 per day. The reality is that 87 per cent of them have accepted wages in this category in the past. Alternatively put, only
13 per cent of the day labourers received wages higher than R70 per day as opposed to the 83.3 per cent of them who indicated that amount as the minimum they are prepared to work for. The average daily income in this informal labour market ranges between R41.24 as a minimum average and R50.17 as a maximum average. This is lower than the figure of between R50 and R60 quoted by Mocke (2004: 12). One must remember that the article of Mocke featured day labourers in Cape Town where the demand and supply factors are obviously different than in Pretoria.

The unfulfilled expectations and resultant seemingly low levels of income experienced by the day labourers are not their only problem. Their situation is further worsened by the income uncertainty they experience. This is evident from the huge difference between the income earned in a good month in this labour market and the amount earned during a very bad month of activity as day labourers in Pretoria. Figure 5 bears testimony to this.

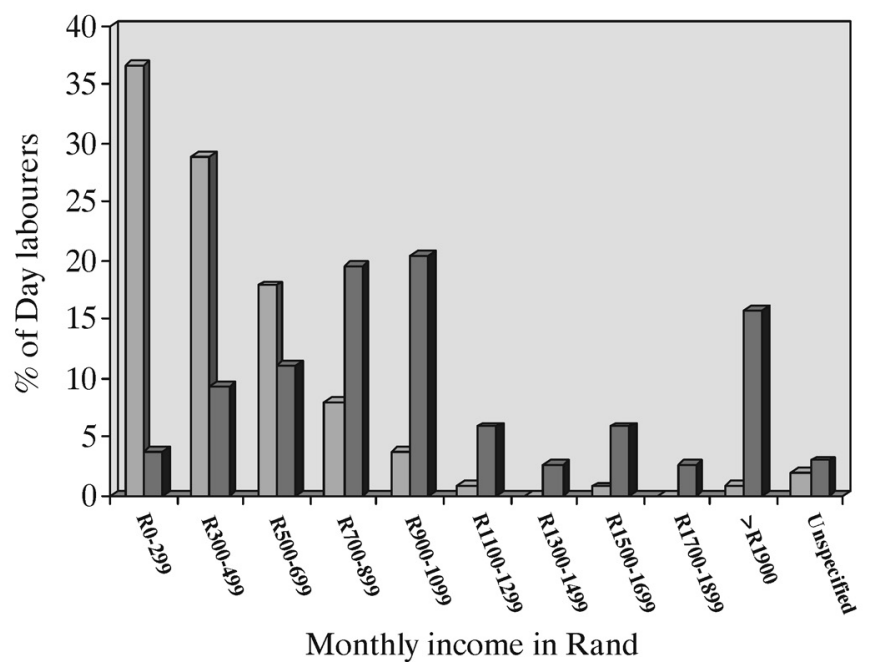

$\%$ of Day labourers in bad month

$\%$ of Day labourers in good month

Source: Survey data

\section{Figure 5}

The monthly income of day labourers in Pretoria in a good month vs. a bad month

In a good month of earnings almost a third (32.7 per cent) of the sample population earn between R800 and R1 100 per month. There is even a group of 37 day labourers (15.7 per cent) that maintained that they earned more than R1 900 per month during good times. The average monthly income in a good month of earnings is calculated at R1187.46. This paints a fairly positive picture, but is the exception rather than the rule.

When times are bad, however, the picture changes dramatically. In a typical month of bad 
earnings, the vast majority of day labourers in Pretoria earn much lower monthly wages. In fact, almost two thirds (65.5 per cent) of the research population earn less than R500 per month during such periods. A total of 83.4 per cent of these people earn less than R700 per month in bad times. This culminates in decreases of more than 50 per cent. In this case the average monthly income drops to R401.93. This uncertainty has a huge impact on the ability of day labourers to plan ahead. The fieldwork brought this uncertainty to the fore through the anxiety expressed by the respondents in terms of whether or not they will be able to support their dependents each month.
Because of the huge fluctuations in the fortunes of the participants in this informal labour market, it is very difficult to accurately estimate a consistent average income earned by the respondents. An attempt to obtain some indication of the value of this variable was however made. The respondents were asked to indicate the amount that was earned by them in the month preceding the interview. This figure was calculated at R672.17 for August 2004.

The above estimates of the average monthly income of day labourers were compared with the minimum living standard monthly income in South Africa. The results are summarised in Table 2 below.

\section{Table 2}

Average monthly income of day labourers compared to the sustainable living standard of monthly income in South Africa and Pretoria.

\begin{tabular}{|c|c|c|c|c|}
\hline $\begin{array}{l}\text { Arrhythmic } \\
\text { average monthly } \\
\text { income of day } \\
\text { labourers in a } \\
\text { good month in } \\
2004 \\
\text { R } 1187.46\end{array}$ & $\begin{array}{l}\text { Arrhythmic } \\
\text { average monthly } \\
\text { income of day } \\
\text { labourers in a } \\
\text { bad month in } \\
\mathbf{2 0 0 4} \\
\text { R } 401.93\end{array}$ & $\begin{array}{l}\text { Arrhythmic } \\
\text { average monthly } \\
\text { income of day } \\
\text { labourers in } \\
\text { August } 2004 \\
\text { R } 672.17\end{array}$ & $\begin{array}{l}\text { National poverty } \\
\text { line per adult } \\
\text { equivalent, } \\
\text { expressed in } \\
\text { 2004 prices' } \\
\text { R } 394 \text { per month }\end{array}$ & 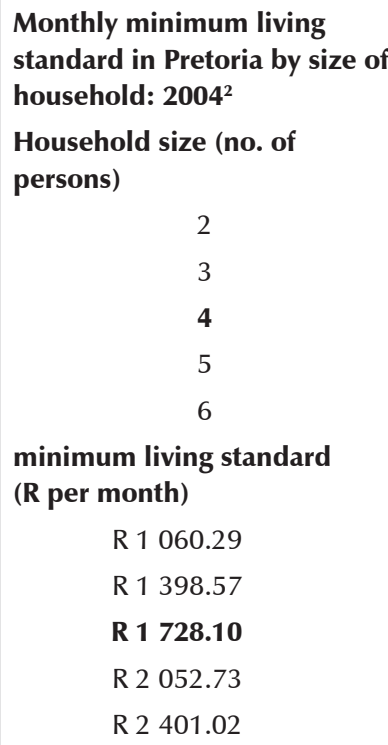 \\
\hline
\end{tabular}

Source: ${ }^{1}$ United Nations Development Programme (2003: 6)

${ }^{2}$ Martins (2004: 4)

More than half (57.6 per cent) of the sample population earned less than R700 in the month preceding the survey. An even more significant statistic is the fact that 24.7 per cent of the day labourers received an income of less than R300 per month. This is 15.2 per cent lower than the national poverty line of R354 per month per adult in 2002 (United Nations Development Programme, 2003: 6). When adjusted for inflation by utilising the official CPIX figures, the national poverty line increases to R394 per month in terms of 2004 prices. Now the R300 per month is 24 per cent lower (Statistics South Africa, 2006b: 1). This section of the sample population is without doubt all living in abject poverty. They cannot even sustain themselves, let alone the average of four people that depend on their income. If the very conservative estimate of the R394 per month is used as a benchmark, it is evident that on average a day 
labourer will barely be able to support himself in months that can be classified as bad in terms of income earned. One must remember that at least 36.6 per cent of them are even then still living beneath the poverty line.

The estimates of Martins (2004: 4) paint a much more sombre picture. These estimates are important as it was established that the average day labourer supports four people with his income. Even if it is assumed that all of them reside within the same dwelling, it is beyond doubt that day labourers will struggle to support these dependents even in months that can be classified as extremely good in terms of income earning possibilities. The extent of the poverty gap for each scenario is calculated and summarised in table 3 .

Table 3

Poverty gap of day labourers supporting four dependents under various income scenarios

\begin{tabular}{|l|l|l|}
\hline $\begin{array}{l}\text { Poverty gap of day labourers in a } \\
\text { good month }\end{array}$ & $\begin{array}{l}\text { Poverty gap of day labourers in a } \\
\text { bad month }\end{array}$ & $\begin{array}{l}\text { Poverty gap of day labourers in } \\
\text { August 2004 }\end{array}$ \\
$40.2 \%$ to $35.4 \%$ & $77.1 \%$ to $71.4 \%$ & $62.8 \%$ to $27.4 \%$ \\
\hline
\end{tabular}

Source: Author's calculations using survey data together with the estimates of Martins (2004: 4)

These findings correspond with other studies on informal sector activities in the Pretoria region. Lighthelm (2004) determined that the average monthly turnover and gross profit for informal market activity in Tshwane (Pretoria) was R3420 and R1010 per month respectively. This is only half the required amount to sustain the average African household in Pretoria (Martins, 2004: 4).

The above data prove beyond all reasonable doubt that being a day labourer can provide a means of survival, but on average inadequate income is earned in order to support family and other dependents.

\section{7}

\section{Summary and conclusions}

Unemployment remains one of the major macroeconomic challenges facing this country. In spite of recent positive news on the unemployment front, the foreseeable future is evidenced by large numbers of unemployed people. The investigation of unemployment in South Africa requires the availability of reliable microeconomic data. This type of data is not always available in terms of specific activities in the informal economy. Studying the employment history of day labourers and the income earned by them, provides additional data and valuable insight into the complex nature of unemployment in South Africa.
Against this background, the aim of this paper is twofold. The first objective is to address the lack of research on informal labour markets by focusing on the day labourers in Pretoria as a case study. The second objective is to investigate the employment history of day labourers in Pretoria and the income earned by them.

Day labourers involved in this study were mainly male, fairly young, generally low skilled and working under harsh conditions. The occurrence of social problems threatening the social fabric of these communities is a reality. The concerns raised by the respondents in terms of being able to take care of their dependents testify to that. On average, each day labourer supports four people (including himself) with the income earned in this informal labour market. More than half of the respondents (56.2 per cent) support up to four people. This emphasises that unemployment is not merely an issue involving individuals. It should be analysed within the context of households.

Only 30.1 per cent of the sample population of day labourers was hired by the same employer repeatedly (more than three times). This shows that the day labourers enjoy very little, if any, security in terms of the possibility of earning an income. It is not surprising then that 90.1 per cent of them maintained that they are looking for full-time employment.

In contrast to many other informal activities, a significant portion (42.1 per cent) of day labourers in Pretoria previously held formal 
sector jobs. It is evident that many of the respondents held stable employment for a relatively long period of time before becoming unemployed. Long spells of unemployment and low skills levels, make it extremely difficult for day labourers to return to the formal sector. As the study showed, there are also those who enter the labour market for the first time, but cannot secure jobs. This experience is in line with other informal sector activities.

Respondents who held formal sector employment cited layoffs and quitting as the main reasons for losing their jobs. Layoffs mainly relate to cyclical and structural changes in the economy, while the number of people who lost their jobs for disciplinary reasons is surprising. It accentuates that a lack of discipline, work ethic and misconduct also contribute to unemployment. This warrants further investigation.

Day labourers rarely receive the wage they would like to work for. Unfulfilled expectations are not their only problem. Their situation is further worsened by the income uncertainty they experience. This is evident from the huge difference between the income earned during a good month and the amount earned during a very bad month in this market in Pretoria. The average monthly income in a good month of earnings is calculated at R1187.46 as opposed to R401.93 earned in a bad month.

The above estimates of the average monthly income of day labourers were compared with the minimum monthly income rate in South Africa. The results are discouraging. The average day labourer supports four people with his income. Day labourers will struggle to support these dependents even in months that can be rated as extremely good in terms of income earning possibilities. The extent of the poverty gap for each scenario was calculated and can be as high as 77.1 per cent in a bad month. These findings correspond with other studies on informal sector activities in the Pretoria region.

Being a day labourer can provide a means of survival, but on average inadequate income is earned to support family and other dependents. To further appreciate the underpinnings of informal labour market activities like these, a repeat of this and further surveys is needed to determine the transitions in this market and how they relate to the economic well-being of the people involved in it.

8

\section{References}

1 ALTMAN, M. (2006) "Low skill work in South Africa”, Paper presented to: IZA/World Bank Conference on Employment \& Development in Berlin, Germany, May 25 - 27, 2006.

2 BARKER, F. (2003) The South African Labour Market, (4 $4^{\text {th }}$ ed.) Van Schaik: Pretoria.

3 BLAAUW, P.F. \& BOTHMA, L.J. (2003)

"Informal labour markets as a solution for unemployment in South Africa - A case study of car guards in Bloemfontein", South African Journal of Human Resource Management, 1(2): 40-44.

4 BLESS, C. \& HIGSON-SMITH, C. (1995) Fundamentals of Social Research Methods - an African Perspective, ( $2^{\text {nd }}$ ed.) Juta: Cape Town.

5 CHETTY, S. (2002) "Creating a sustainable climate for fixed capital formation in the South African Development Community (SADC)" Research paper No 0205, Department of Economics: RAU.

6 DEVEY, R.; SKINNER, C. \& VALODIA, I. (2003) "Informal economy employment data in South Africa. A critical analysis", Paper presented at the TIPS AND DPRU FORUM 2003, The Challenge of Growth and Poverty: The South African Economy Since Democracy, 8 - 10 September 2003, Indaba Hotel, Johannesburg.

7 KINGDON, G. \& KNIGHT, J. (2001a) "What have we learnt about unemployment from microdatasets in South Africa?" Centre for the Study of African Economies, Department of Economics: University of Oxford.

8 KINGDON, G.G. \& KNIGHT, J. (2001b) "Why high open unemployment and small informal sector in South Africa?" Centre for the Study of African Economies, Department of Economics: University of Oxford.

9 KRIGE, D. (1988) “The prospects for informal small businesses in KwaMashu", Development Southern Africa, 5(2): 168-185.

10 LIGTHELM, A.A. (2004) "Informal markets in Tshwane: Entrepreneurial incubators or survivalist reservoirs?" UNISA Bureau of Market Research Report, No 335.

11 LOOTS, A.E. (1998) "Job creation and economic growth", The South African Journal of Economics, 66(3): 319-336. 
12 LUND, F. (1998) "Women street traders in urban South Africa: A synthesis of selected research findings", CSDS Research Report, no. 15, University of Natal: Durban.

13 MAISEL, C. (2003) Proposal: Men on the Side of the Road: Project to Raise Funds for the Implementation of the 2004/2005 Budget, Roggebaai: Cape Town.

14 MARTINS, J.H. (2004) "Minimum and supplemented living levels in the main and other selected urban areas of the RSA", UNISA Bureau of Market Research Report, No 334, March.

15 MOCKE, L. (2004) "Die man langs die pad kan en wil graag werk", Article published in Sake-Beeld, in Beeld, 17 August 2004: 12.

16 MULLER, C. (2003) "Investigating South Africa's informal sector: Measurement, participation, and earnings", Unpublished Masters Thesis, University of Natal: Durban.

17 ROGERSON, C.M. \& BEAVON, K.S.O. (1980)

"The awakening of 'informal sector' studies in Southern Africa", South African Geographical Journal, 62(2): 175-190.

18 SCHENCK, R. \& LOUW, H. (2005) “An exploratory study on day labourers in Elardus Park Pretoria”, Social Work/Maatskaplike Werk, 41(1): 84-95.
19 SCHLEMMER, L. \& LEVITZ, C. (1998) "Unemployment in South Africa - The facts, the prospects and an exploration of solutions", South African Institute of Race Relations: Johannesburg.

20 STATISTICS SOUTH AFRICA (2003) Labour Force Survey, September 2002: Pretoria.

21 STATISTICS SOUTH AFRICA (2006a) Labour Force Survey, September 2005 Pretoria.

22 STATISTICS SOUTH AFRICA (2006b) Consumer Price Index (P0141.1): Metropolitan and Other Urban Areas - CPIX: Pretoria.

23 UNITED NATIONS DEVELOPMENT PROGRAMME (UNDP) (2003) South Africa Human Development Report 2003, Oxford University Press: Cape Town.

24 VALODIA, I., LEBANI, L., SKINNER, C. \& DEVEY, R. (2006) "Low wage and informal employment in South Africa", Transformation, Critical Perspectives on Southern Africa, 60(2006): 90-126.

25 WHITEFORD, A. \& VAN SEVENTER, D.E. (1999) Winners and losers: South Africa's changing income distribution. 